\title{
Picture Stories
}

\section{Cerebrospinal fluid pseudocyst: A rare complication of ventriculo- peritoneal shunting}

*R M T M Gunawardena ${ }^{1}$, A K Lamahewage ${ }^{2}$

Sri Lanka Journal of Child Health, 2018; 47(2): 181-182

DOI: http://dx.doi.org/10.4038/sljch.v47i2.8491

(Key words: CSF pseudocyst, VP shunt complications, VP shunt)

\section{Introduction}

Hydrocephalus is the commonest condition treated in paediatric neurosurgery ${ }^{1}$. Ventriculo-peritoneal (VP) shunting is a well-known treatment modality for hydrocephalus. Formation of a localized intraabdominal cerebrospinal fluid (CSF) collection, known as a CSF pseudocyst, is a rare complication of this procedure. We present a seven month old baby who presented with this complication.

\section{Case report}

A 7 month old baby girl, who underwent VP shunting at 1 month of age for hydrocephalus, was referred to our casualty. Mother noted progressive distention of child's abdomen over the last week. There were no features of intestinal obstruction. Child was afebrile and active. On examination, abdomen was distended but non tender without any distinctive masses. Inflammatory parameters were normal. Supine x-ray of abdomen showed increased density of the lower abdomen which was more prominent on the left side with displaced bowel loops toward the right upper quadrant (Figure 1).

A localized intraabdominal CSF collection was suspected and ultrasound scan showed a collection without septa occupying the pelvis and left side of abdomen extending up to right iliac fossa. Open drainage of collection was performed and near total excision of sac wall was done. The catheter tip, which was within the cyst (Figure 2), was repositioned in a different abdominal quadrant. No organisms were isolated from the sample of intracystic CSF sent for culture. Recovery was uneventful and baby was discharged on day 3 following surgery.

\footnotetext{
$\overline{{ }^{1} \text { National Hospital of Sri Lanka, }{ }^{2} \text { Lady Ridgeway }}$ Hospital for Children, Sri Lanka

*Corresponding author: mihirangn@gmail.com (Received on 05 March 2017. Accepted after revision on April 2017)

The authors declare that there are no conflicts of interest

Personal funding was used for the project.

Open Access Article published under the Creative
}

Commons Attribution CC-BY

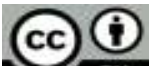

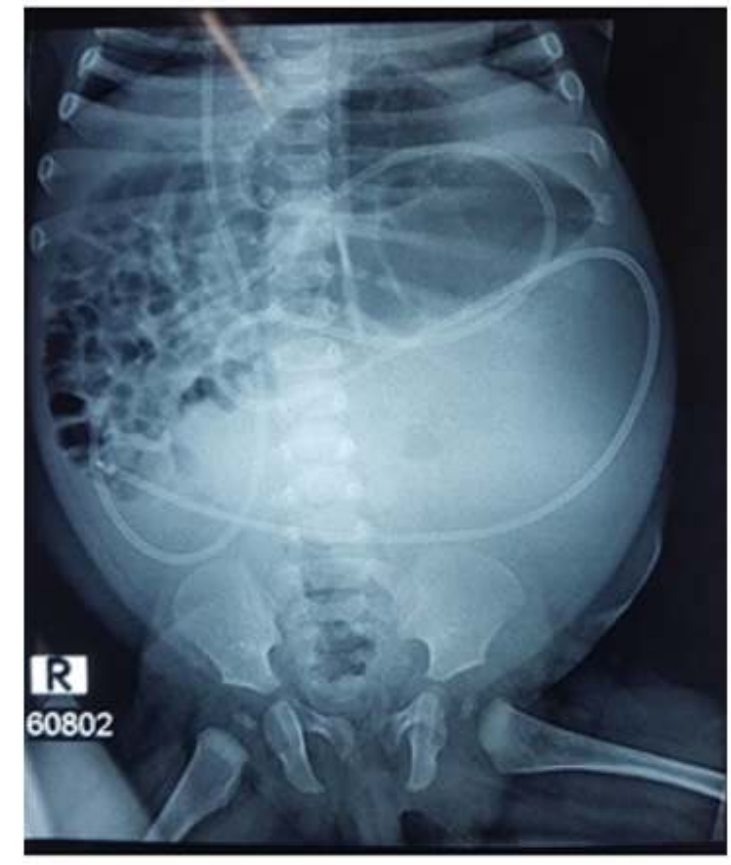

Figure 1: X-ray abdomen with displaced bowel loops

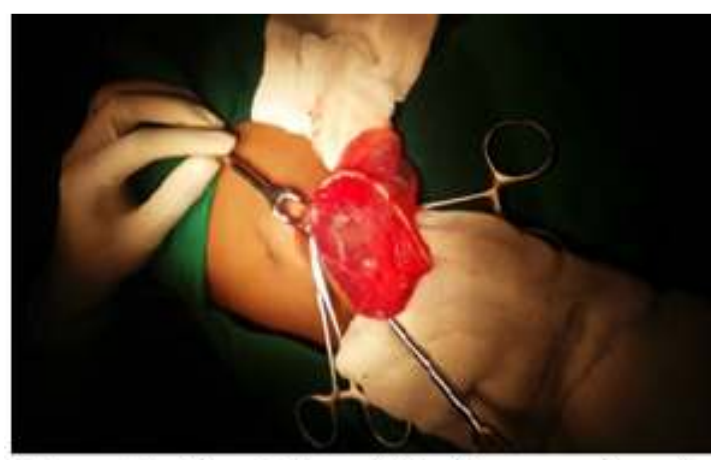

Figure 2: Shunt tip within the pseudocyst

\section{Discussion}

VP shunting since its initial description in 1908 remains the commonest procedure utilized for management of hydrocephalus ${ }^{1}$. Lifetime risk of developing a VP shunt related complication is as high as $80 \%$, and $5-47 \%$ can develop an intraabdominal complication ${ }^{1,2}$. Among the complications at the peritoneal end of the shunt, infection, formation of intraperitoneal pseudocyst, shunt migration, bowel perforation, intestinal 
volvulus and mesenteric pseudotumour have been described ${ }^{2}$.

Formation of a localized CSF collection contained by a fibrous wall without an epithelial lining is defined as a CSF pseudocyst and it can complicate up to $0.7-4.5 \%$ of VP shunts ${ }^{3}$. Children with this complication commonly present with features of raised intracranial pressure related to shunt dysfunction and abdominal pain. In adults local symptoms and signs predominate such as abdominal pain, distention, nausea and vomiting ${ }^{2}$. In the case series described by Ghritlaharey et al, all three children presented with abdominal distention although they were older than our child, and two of them had a picture suggestive of intestinal obstruction ${ }^{4}$.

The exact pathogenesis of CSF pseudocyst is still obscure $^{4}$. The ensheathing of the peritoneal end of the catheter occurs as a response to inflammation most commonly secondary to infection, and in $80 \%$ of pseudocysts infection was recognized as the predisposing factor ${ }^{1,2}$. Other risk factors for this condition are previous intra-abdominal surgery, shunt revisions, high protein content in the CSF and allergic reactions to the catheter ${ }^{1}$. In our patient infection was excluded by the sterile CSF culture and we were unable to identify an obvious aetiologic factor. Ultrasound and computed tomography (CT) are the imaging modalities of choice for confirmation of the diagnosis ${ }^{1,4}$. Plain $x$-ray of the abdomen can be a useful adjunct when the typical displacement of bowel loops are shown ${ }^{2}$ as in our patient.

Associated infection is a critical factor in determining management of this condition ${ }^{3}$. Guided aspiration of cyst content and culture is used to exclude infection ${ }^{3,4}$ and proven or suspected infection needs shunt externalization with later repositioning ${ }^{3}$. The shunt may be positioned in a different quadrant of the abdomen or alternatives methods of CSF drainage such as ventriculo-atrial shunts, ventriculo-pleural shunts and endoscopic third ventriculostomy can be utilized ${ }^{5}$. Simply repositioning the shunt tip in the right atrium or the pleural cavity leads to cyst collapse as there is no secretory epithelial lining ${ }^{4}$. Ghritlaharey et al performed exploratory laparotomies, near total excision of the cyst walls and immediate repositioning of the shunt tip in the abdominal cavity in three patients ${ }^{4}$ and we utilized a similar management strategy. However, in the presence of infection shunt externalization with delayed repositioning is a better option. In selected patients laparoscopic repositioning of the catheter tip and repeated guided aspiration of the cyst are viable options $^{3,4}$.

CSF pseudocyst is an uncommon complication of VP shunting for hydrocephalus. Clinical suspicion and appropriate imaging leads to the correct diagnosis. Associated infection is the most critical factor in deciding the course of management.

\section{References}

1. Boia ES David VL, Emanuela Verenca, Corina Stanciulescu, Alexandra Pelivan, Popoiu MC. Extraperitoneal cerebrospinal fluid pseudocyst formation following ventriculo-peritoneal shunt. Jurnalul Pediatrului 2013; 16(64): 36-38.

2. Chung JJ, Yu JS, Kim JH, Nam SJ, Kim MJ. Intraabdominal complications secondary to ventriculo-peritoneal shunts: CT findings and review of the literature. American Journal of Roentgenology 2009; 193(5):1311-7.

https://doi.org/10.2214/AJR.09.2463

PMid: 19843747

3. Lu-Chih K, Fei-Shih Y, Jon-Kway H. Intraperitoneal cerebrospinal fluid pseudocyst: a case report. Chinese Journal of Radiology 2005; 30: 129-32.

4. Ghritlaharey RK, Budhwani KS, Shrivastava D K, Jain A J, Gupta G, Kushwaha AS..CSF pseudocysts peritoneal cavity following V P Shunt surgery: Report of three cases in children and review of literature. Journal of Indian Association of Pediatric Surgeons 2006; 11(1); 41-43.

https://doi.org/10.4103/0971-9261.24638

5. de Oliveira RS, Barbosa A, Vicente YA, Machado HR. An alternative approach for management of abdominal cerebrospinal fluid pseudocysts in children. Childs Nervous System 2007; 23(1):85-90. https://doi.org/10.1007/s00381-006-01837

PMid: 16944175 